\title{
Our Surgical Outcomes for Congenital Penile Curvature
}

\author{
Erdal Benli ${ }^{1}$, Ahmet Yuce ${ }^{1}$, Abdullah Cirakoglu ${ }^{1}$, Yeliz Kasko Arıc1 ${ }^{2}$ \\ ${ }^{1}$ Department of Urology, Ordu University Faculty of Medicine, Ordu, Turkey \\ ${ }^{2}$ Department of Biostatistics and Medical Informatics, Ordu University Faculty of Medicine, Ordu, Turkey
}

Received: 05 June 2020, Accepted: 27 November 2020, Published online: 31 December 2020

(C) Ordu University Institute of Health Sciences, Turkey, 2020

\begin{abstract}
Objective: Patients with congenital penile curvature (CPC) frequently require surgical treatment. However, patients cannot access the treatment required everywhere. The common reason for this is the insufficient information and experience of the people offering treatment. This study was planned to attract attention to the topic and present our 5-year experience.

Methods: The outcomes for 17 patients with tunical plication due to CPC were retrospectively analyzed. During attendance, ages and complaints were recorded. Data about the curvature angle, satisfactory straightening, and residual curvature in the process of surgery and after surgery were analyzed.

Results: Data from 17 CPC patients abiding by the criteria were used. The mean age of cases was $18.06 \pm 4.54$ years. Mean curvature angle was identified as $55.8 \pm 17.8^{\circ}$. None of the patients had known trauma history or pain at attendance $(0 / 17,0 \%)$. All patients perceived this disease as a problem $(17 / 17,100 \%)$. During mean 9.4 \pm 3.5 (6-15) month follow-up, 15 of 17 patients $(88.2 \%)$ were identified to have satisfactory penile correction. Clinically significant residual curvature $\left(>20^{\circ}\right)$ was identified in 2 of 17 patients $(11.8 \%)$. Two of the 17 patients $(11.8 \%)$ reported mild, insignificant, and not uncomfortable $\left(<20^{\circ}\right)$ curvature. Additional surgical procedures were not required for residual curvature.

Conclusion: Surgical correction is frequently unavoidable for treatment of this disease. As seen in our study, this surgical procedure is a simple, reliable, and effective treatment choice. However, many people offering treatment are known to avoid these patients or these surgical treatments. Though there are many reasons for this, according to our experience, the most important cause is lack of sufficient knowledge and experience. It is a very difficult situation for urologists to avoid curvature surgery, commonly found among urological diseases. We think it will be beneficial to provide the necessary information and experience for dealing with these patients during or after specialization training.

Key words: Congenital penile curvature, penile plication, surgical repair.
\end{abstract}

Suggested Citation: Benli E, Yuce A, Cirakoglu A, Kasko Arici Y. Our Surgical Outcomes for Congenital Penile Curvature. Middle Black Sea Journal of Health Science, 2020; 6(3):288-293.

Address for correspondence/reprints:

Ahmet Yüce

Telephone number: +90 (506) 2176164
E-mail: ahmetyuce7@gmail.com

DOI: $\quad 10.19127 / \mathrm{mbsjohs} .718799$

ORCID-ID 0000-0003-2931-3927 


\section{Introduction}

Congenital penile curvature (CPC) is bending of the penis during erection frequently in lateral or ventral direction. The definite incidence in society is not fully known. However, it is estimated to affect $0.5-10 \%$ of men (Kramer et al., 1982; Yachia et al., 1993; Montag and Palmer, 2011; Ziegelmann et al., 2019). As this curvature does not cause discomfort for some patients or they accept it as normal, they do not attend doctors, so it is probable there are many patients who are not diagnosed. Diagnosis remains silent until functional limitations occur during sexual relations.

This disease may be confused with Peyronie disease where the curvature is variable, and which generally occurs at adult ages. Peyronie disease has different underlying pathology and the fibrotic disease is related more to the tunic albuginea (AlThakafi and Al-Hathal, 2016). In Peyronie disease the patient is frequently sexually active, and their history includes new onset of curvature and sexual disorder. Physical examination finds palpable plaque (tunical thickening) and this plaque limits penile elasticity. The etiology of this disease has not been fully explained. It is thought that microtraumas occurring during sexual relations begin an inflammatory process resulting in fibrosis and this causes plaque development (Al-Thakafi and Al-Hathal, 2016; Jiang et al., 2018). It may be easily distinguished from CPC with detailed assessment.

Treatment of curvature frequently requires surgical treatment. The aim of surgery is to ensure correction to allow penetration of the penis. For successful surgery, serious training and experience is mandatory. However, according to our experience, curvature surgery has not found its rightful place among routine urologic surgical procedures. As a result, people offering treatment who do not see themselves as sufficient about the topic avoid these patients and surgical procedures as much as possible. This study was designed to draw attention to this topic.

The aim of this study is to present a 17-case CPC series and to share our experience about this topic to motivate people or clinics who are new to this procedure.

\section{Methods}

\section{Study design and patients}

Patient information was obtained from retrospective screening of records.
Data from 17 CPC patients attending our clinic from August 2014 to 2019 with information accessed were used.

Patients with hypospadias, Peyronie disease, and urethral surgery history were excluded from the study.

Demographic characteristics, history and physical examination findings, and preoperative and postoperative results were reviewed.

\section{Clinical Assessment}

All patients were evaluated preoperatively with detailed history and physical examination including sexual history, trauma, medication use, time of curvature onset and progression. The penile shaft was examined carefully in terms of pathologies that may be confused with CPC such as Peyronie disease. Pictures taken by patients of their erect penis were examined. If necessary, cases had intracavernosal injection performed and advanced tests were used to assess penile curvature or penile hemodynamics. Only cases who were stable in terms of curvature were taken for surgery.

After surgery, success was defined as satisfactory penile straightening as stated by the patient, while failure was the inverse. Continuation of curvature while patients remained satisfied or could maintain sexual life was defined as residual curvature.

\section{Surgical Technique}

The surgical procedure was completed under general anesthesia for all cases. At the start of surgery, artificial erection was induced in every case to assess curvature. Later, the penis was degloved with an incision on the circumcision line. The Buck fascia and neurovascular bundle (NVB) were carefully removed or lifted from the tunica albuginea. Later penile erection was induced and the tunica albuginea was held with Allis clamps on the opposite side to the curvature with the aim of straightening the penis. Later the Allis clamps were removed. The two marks with nearly $5 \mathrm{~mm}$ length left on the tunica albuginea by the clamp were used as plication suture sites. Two plication sutures were made with 2-0 unabsorbable sutures so the knots remained inside. The distance between the Allis clamps was adjusted according to the severity and location of curvature. After the procedure was completed, erection was induced again, and curvature was checked. If there was continuing curvature, the procedure was repeated with additional plication. After the desired straightness was obtained, the layers were anatomically closed, and the penis had compression bandaging with koban bandage. 
For 2 weeks postoperative, a penile rehabilitation regime was recommended inducing penis traction with penile massage and the hand to prevent development of contraction and to initiate rapid healing. After patients were discharged, they were called for check-up 10 days later. Later they were called for check-ups every 3 months for the first year and then annually after that.

\section{Statistical Analyses}

Normal distribution of continuous data was checked with the Shapiro-Wilk test, while homogeneity of group variance was checked with Levene test. Comparison of variables abiding by assumptions was performed in two groups with the student $t$ test and data are expressed as mean \pm standard deviation. Variables not abiding by assumptions were compared in two groups with the Mann-Whitney $U$ test and data are expressed as median [interquartile range (IQR)]. Categoric variables are expressed as frequency and analyzed with Pearson chi-square analysis. All calculations were performed with SPSS v.25 (IBM corp, Chicago, IL, USA) statistical program. Statistical significance used $\mathrm{p}<0.05$.

\section{Results}

There were 17 CPC patients who abided by the criteria. Mean age at attendance was $18.06 \pm 4.54$ years. Patients did not describe trauma history or pain $(0 / 17,0 \%)$. The whole group perceived penile curvature as a frustrating problem $(17 / 17,100 \%)$ (Table 1).

Table 1: Patient complaints with CPC

\begin{tabular}{lc} 
Complaints & $\mathrm{n}(\%)$ \\
\hline Penile Pain & $0(0 \%)$ \\
Changes in curvature & $0(0 \%)$ \\
Psychological stress & $17(100 \%)$ \\
Trauma history & $0(0 \%)$
\end{tabular}

Examination of patients identified mean curvature angle of $55.8 \pm 17.8^{\circ}$. In 9 of the 17 patients $(42.9 \%)$ curvature was towards ventral, while in $5(23.8 \%)$ it was dorsal and in 12 $(57.1 \%)$ it was lateral. During the surgery, the number of points held by Allis clamps were $2.8 \pm 1.2(1-5)$ and the number of sutures was identified as $5.65 \pm 2.5$ (Table 2).
Table 2: Examination findings for patients

\begin{tabular}{lc}
\hline \multicolumn{1}{c}{ Cases undergoing surgery } & $\mathrm{n}(\%)$ \\
\hline & \\
Primary curvature angle (mean \pm std) & $55.88 \pm 17.8(40-$ \\
Primary curvature direction & $90)$ \\
Ventral n (\%) & \\
Dorsal n $(\%)$ & $9(42.9 \%)$ \\
Lateral n (\%) & $5(23.8 \%)$ \\
Number of points held with Allis clamp & $12(57.1 \%)$ \\
(mean \pm std) & $2.8 \pm 1.2$ \\
\hline
\end{tabular}

With mean 9.4 \pm 3.5 (6-15) months of follow up, 15 of 17 patients $(88.2 \%)$ were identified to have satisfactory penile correction. Clinically significant residual curvature $\left(>20^{\circ}\right)$ was identified in 2 of 17 patients $(11.8 \%)$. In 2 of 17 patients, mild, insignificant curvature $\left(<20^{\circ}\right)$ that was not a source of discomfort was reported (Table 3). Two patients described uncomfortable curvature in the early postoperative period (2/17); however, this problem was resolved during check-ups (6 months). No patient required additional surgical procedure for residual curvature. In the postoperative period, no problem was encountered that could not be resolved in the short term with simple precautions. There was no problem encountered related to the surgical field or to feeling sutures.

Table 3: Surgical outcomes

\begin{tabular}{lc}
\hline Postoperative outcomes & $\mathrm{n}(\%)$ \\
\hline Satisfactory correction $(\mathrm{n}, \%)$ & \\
Residual curvature $(\mathrm{n}, \%)$ & $15 / 17(88.2 \%)$ \\
Re-surgery for residual curvature & $3 / 17(17.6 \%)$ \\
$(\mathrm{n}, \%)$ & $0 / 17(0 \%)$ \\
Complication requiring re-surgery & $0 / 17(0 \%)$ \\
$(\mathrm{n}, \%)$ & \\
\hline
\end{tabular}

\section{Discussion}

CPC is a commonly observed urologic pathology. The underlying cause of this disease is not fully known. Causes that have received most focus include asymmetric corporal length, fibrosis of the Buck or dartos fascia, and congenitally shortened urethra (Donnahoo, 1998). Frequently noticed in the childhood period or in the sexually-active period, the search for treatment for curvature or functional problems begins (Ebbehoj and Metz, 1987; Zahran et al., 2012). This process may be very frustrating and uncomfortable for both patient and parents. Psychological problems like loss of self-confidence, introversion, disrupted social relationships, distancing from the opposite sex, anxiety and depression are frequently seen in this period. A study showed that these people even avoid marriage (Paulson, 1995). 
The most frequent reason for attending hospital among our patients was curvature and problems developing linked to this curvature, in accordance with the literature. We observed that the traumatizing effect on patients increased in cases who became aware of the problem during sexual relations especially (penetration or functional disorder). People involved in treating this disease should be aware that these patients require more interest and time compared to other diseases.

For diagnosis of this disease, detailed medical and sexual history is generally sufficient. In some situations, self-portraits taken during erection or imaging after intracavernosal injection may be required, especially for differential diagnosis (Kızılay et al., 2017). In our clinic, we see these images as an inseparable part of diagnosis. Self-portraits are very beneficial for recording the disease, identifying the degree of curvature and for planning treatment. For identification of curvature levels, patient statements may be misleading (Liguori et al., 2018).

Generally, $30-45^{\circ}$ curvature is used as the threshold value for treatment of these patients (Walsh et al., 2013). When the literature about CPC is examined, though many treatment methods have been described, the actual treatment is surgical correction. Though the area of use is limited, some noninvasive methods have been described. However, most of these are methods used after surgery (Bella et al., 2018). Procedures during surgery are in the form of lengthening the short edge using a variety of material (vein grafts, synthetic materials) or shortening the long edge. This shortening may be in the form of plication or removing elliptical pieces from the tunica (Gunlusoy et al., 2003). The Nespit method and a few different plication techniques are the most commonly used surgical methods (Lee et al., 2004).

The plication technique is the most commonly chosen method. The reason for this includes significant advantages like being less invasive and simple, adjustable, less hemorrhage risk, low postoperative erectile dysfunction risk and easy learning curve (Salem, 2018). We chose this technique due to our experience in our training clinic, ease of learning and implementation, and having very effective outcomes.

When the literature is examined, the success rates for surgery performed for curvature is reported as 83$100 \%$ independent of method. The reason for this broad interval is due to differences in the success criteria used in studies. In our study, in accordance with the literature, we identified the satisfactory correction rate as $88.2 \%$. Ziegelmann et al. published outcomes from 35 CPC patients. They reported success rate of $90 \%$ defined as satisfactory correction as a result of the study (Ziegelmann et al., 2019). A study from Turkey published the outcomes for 50 CPC patients. The success rate in this study was reported as 72\% (Kizilay et al., 2017). Another study reported the success for curvature surgery was generally $88 \%$ (Gunlusoy et al., 2003).

Patients attending with residual curvature continuing after surgery should be carefully evaluated. Assessment of correction is a very variable or subjective situation. For people with active sexual lives, the critical point required for success is whether the penis is functional or not. Residual curvature may not be significant if it does not affect penis function. Some authors have recommended a classification of success as full straightening or residual curvature without discomfort $\left(<20-30^{\circ}\right)$. Especially for patients with insignificant residue, the term functional straight penis may be beneficial (Nehra et al., 2015). Ziegelmann et al. reported their insignificant residual curvature rate as $20 \%$ (Ziegelmann et al., 2019). In our study, this was identified in 2 of 17 patients $(11.8 \%)$ and no additional surgical procedure was required.

In some residual curvature patients, correction with additional surgeries is unavoidable. This situation is a frustrating event for both patient and doctor. There may be more than one reason for this, with possible causes including asymmetric scar, differences in erection induced during surgery and erection levels at home, surgical experience and complicated cases (Cordon et al., 2017). When the literature is examined, the re-surgery rates for residual curvature vary from $0-3 \%$ (Kuehhas and Egydio, 2012). Surgeries to correct residual curvature are more difficult compared to primary surgery. As a result, patients need to be informed as necessary about the potential risks of re-surgery. Additionally, corrective sutures may cause shortening of the penis or unnecessary corrections.

In our study, no patient was observed to have curvature requiring re-surgery. We think it is necessary to avoid surgical procedures for patients with insignificant residual curvature $\left(<20^{\circ}-30^{\circ}\right)$ or who do not have problems during sexual relations in relation to this topic. When informed as necessary, most patients do not feel they require surgery for curvature without clinical significance. The problem after another surgery is pain during erection or sutures being felt. In some studies, the use of unabsorbable sutures is reported to be associated with some problems like irritation during erection or related to knots (Poulsen and Kirkeby, 1995; Baskin and Lue, 1998). A study reported discomfort related to knots or 
painful erection at rates of $12 \%$ and $11 \%$. In our patients we used unabsorbable sutures. Our patients were not observed to have any problems related to knots or pain after the surgery.

As seen in the literature and from our study results, curvature surgery is a very effective and reliable treatment method. However, most patients cannot access this treatment at every health center. In our study, most patients described attending more than one hospital or doctor. We do not know the definite reason for this. Among probable causes are interest in other fields during training (laparoscopy, robot, oncology, etc.) or inability to access sufficient information and experience due to this surgery not being performed in training clinics, legal problems, and potential complications involved in the procedure. Especially problems related to malpractice in recent times may make people providing treatment right in avoiding procedures related to the penis, a matter of self for men. However, as urologists all surgical procedures we perform carry at least if not more risk than curvature surgery. As a result, we think this very reliable and simple surgical procedure should gain its rightful place in specialization training programs. For a variety of reasons, it is unavoidable that some surgical procedures remain for the period after training (Cirakoglu and Benli, 2017 and Benli et al., 2018).

There are some limitations to this study. The main limitations are that the study presents outcomes from a single center, is retrospective and the outcomes of people living with this problem in society are not known. At this point, the use of patient statements to assess postoperative success may cause errors in some cases.

\section{Conclusion}

Congenital penile curvature is a very frustrating situation. Treatment frequently requires surgical correction. We have very reliable, simple and effective treatment choices. Among these techniques, the plication technique we frequently use is very effective with very low complication rates and high patient satisfaction after surgery.

However, many people offering treatment avoid these patients or surgical treatments. The reason for this may be not gaining the necessary experience during specialization training. As a result, necessary information and experience for management of this disease should definitely be obtained during specialization training. However, it is not over for people who do not access sufficient experience during training. Necessary training and course programs can resolve this deficiency with one-on-one live surgeries in centers where this procedure is performed. We think it is necessary to gain the necessary information and experience to manage these patients during or after specialization training.

Ethics Committee Approval: Ethics committee approval was received for this study from Clinical Research Ethics Committee of Ordu University (2020/05)

Peer-review: Externally peer-reviewed.

Author Contributions: Concept- E.B, Design- E.B., A.C., A.Y., Supervision- A.Y., Analysis and/or Interpretation- Y.K.A., Literature Review- E. B., Writing- E. B., Critical Review- A. Y.

Conflict of Interest: No conflict of interest was declared by the authors.

Financial Disclosure: The authors declared that this study hasn't received no financial support.

\section{References}

Al-Thakafi S, Al-Hathal N. Peyronie's disease: a literature review on epidemiology, genetics, pathophysiology, diagnosis and work-up. Transl Androl Urol 2016; 5(3): 280-9.

Baskin LS, Lue TF. The correction of congenital penile curvature in young men. Br J Urol 1998; 81(6): 895-9.

Bella AJ, Lee JC, Grober ED, Carrier S, Benard F, Brock GB. 2018 Canadian Urological Association guideline for Peyronie's disease and congenital penile curvature. Can Urol Assoc J 2018; 12(5): 197-209.

Benli E, Cirakoglu A, Yuce A. Is it over if Radical Prostatectomy (RRP) training is not obtained during assistant education? New J Urol 2018; 13(1): 28-33.

Cordon BH, Osmonov D, Hatzichristodoulou G, Morey AF. Peyronie's penile plication. Transl Androl Urol 2017; 6(4): 639-44.

Cirakoglu A, Benli E. Our experience of the first 30 laparoscopic cases in Ordu University. New J Urol 2017; 12(3): 11-6.

Donnahoo KK, Cain MP, Pope JC, Casale AJ, Keating MA, Adams MC, et al. Etiology, management and surgical complications of congenital chordee without hypospadias. J Urol 1998; 160(3): 1120-2.

Ebbehoj J, Metz P. Congenital penile angulation. $\mathrm{Br}$ J Urol 1987; 60(3): 264-6.

Gunlusoy B, Cicek S, Arslan M, Durmaz K, Nergiz $\mathrm{N}$, Minareci S. Results of Nesbit operation in surgical treatment of penile curvature. Turk J Urol 2003; 29(1): 39-42. 
Jiang H, Gao Q, Che X, Zhu L, Zhang Z, Chen Y, et al. Repeated Micro-Trauma of the Penile Tunica Albuginea: A New Animal Model of Peyronie's Disease. Urol Int 2018; 100(2): 228-39.

Kizilay F, Sahin M, Altay B. Congenital penile curvature results using penile plication technique. Androl Bul 2017; 19(1): 10-15. Kramer SA, Aydin G, Kelalis PP. Chordee without hypospadias in children. J Urol 1982; 128(3): 55961.

Kuehhas FE, Egydio PH. Superficial tunica albuginea excision, using geometric principles, for the correction of congenital penile curvature. BJU Int 2012; 110(11): 949-53.

Lee SS, Meng E, Chuang FP, Yen CY, Chang SY, Yu DS, et al. Congenital penile curvature: long-term results of operative treatment using the plication procedure. Asian J Androl 2004; 6(3): 273-76.

Liguori G, Salonia A, Garaffa G, Chiriacò G, Pavan $\mathrm{N}$, Cavallini G, et al. Objective measurements of the penile angulation are significantly different than self-estimated magnitude among patients with penile curvature. Int Braz J Urol 2018; 44(3): 555-62.

Montag S, Palmer LS. Abnormalities of penile curvature: chordee and penile torsion. Scientific World Journal 2011;11:1470-78.

Nehra A, Alterowitz R, Culkin DJ, Faraday MM, Hakim LS, Heidelbaugh JJ, et al. Peyronie's Disease: AUA Guideline. J Urol 2015; 194(3): 745-53.

Paulson J, Kurkeby HJ. Treatment of penile curvatureretrospective study of 175 patients ope-rated with plication of the tunica albuginea on with Nesbit procedure. Br J Urol 1995; 75 (3): 373-74.

Salem EA. Modified 16-Dot plication technique for correction of penile curvature: prevention of knotrelated complications. Int J Impot Res 2018; 30(3): 117-21.

Walsh TJ, Hotaling JM, Lue TF, Smith JF. How curved is too curved? The severity of penile deformity may predict sexual disability among men with Peyronie's disease. Int J Impot Res 2013; 25(3): 109-12.

Yachia D, Beyar M, Aridogan IA, Dascalu S. The incidence of congenital penile curvature. J Urol 1993; 150(5): 1478-79.

Zahran AR, Abdeldaeim HM, Fouda K, Elgebaly OF. Congenital penile curvature presenting as unconsummated marriage. Repair by 16-dot plication with subjectively reported patient and partner satisfaction. Arab J Urol 2012; 10(4): 42933.
Ziegelmann MJ, Farrell MR, Levine LA. Clinical characteristics and surgical outcomes in men undergoing tunica albuginea plicationfor congenital penile curvature who present with worsening penile deformity. World J Urol 2020; 38(2): 305-14. 